\title{
OneShot-M: A New Device for Close Laparoscopy Pneumoperitoneum
}

\author{
Giovanni Cassata, VD, PhD', Vincenzo Palumbo, MD, PhD ${ }^{2,3}$ (D), \\ Luca Cicero, BD', Antonino De Luca ${ }^{4}$, Giuseppe Damiano, MD, PhD'2, \\ Salvatore Fazzotta, MD', Salvatore Buscemi, MD, PhD $^{2}$, \\ and Attilio Ignazio Lo Monte, MD, PhD
}

\begin{abstract}
Introduction. The induction of pneumoperitoneum is the first and most critical phase of laparoscopy, due to the significant risk of serious vascular and visceral complications. The closed technique for the creation of pneumoperitoneum could lead to several surgical complications. The present study aimed to overcome the complications associated with the insertion of Veress needle, improving its use, and facilitating the rapid creation of pneumoperitoneum. Methods. Thirty large white female pigs were enrolled in our study. A common plunger was modified in order to allow the passage of a $15-\mathrm{cm}$ long Veress needle. This method was applied to 26 laparoscopic procedures (26 pigs) of several specialist branches. Results. OneShot-M close laparoscopy pneumoperitoneum creation device allowed us to obtain pneumoperitoneum quickly in all attempts, without any intraoperative and postoperative complications related to the use of the Veress needle. Conclusion. The use of the proposed device showed an induction time as quick as the standard laparoscopic closed abdominal entry. The patented device is cheap and allows a safe abdominal entry. In addition, abdominal entry is much faster than the classic open technique.
\end{abstract}

\section{Keywords}

abdominal entry, innovation, minimally invasive surgery, operating room technology, Veress needle

\section{Introduction}

Laparoscopy is largely used for diagnostic and therapeutic aims. Since laparoscopic instruments and technical skills have improved, its use has been extended to several areas, including gynecology, general surgery, and urology. ${ }^{1}$ Thanks to better aesthetic results, a shorter hospital stay, and a shorter recovery, several laparoscopic procedures have replaced surgical interventions with open technique. ${ }^{2}$ The minimally invasive approach has become the method of choice for the treatment of abdominal diseases requiring surgery. However, although major laparoscopic complications are rare, involving less than $2 \%$ of cases, laparoscopic procedures are not exempt from risks. ${ }^{3,4}$

The induction of pneumoperitoneum is the first and most critical phase of laparoscopy, due to the significant risk of injury of vascular and gastrointestinal structures. ${ }^{5}$ In fact, more than $50 \%$ of the major laparoscopic complications occur when pneumoperitoneum is created, with a mortality rate ranging from $0.05 \%$ to $0.2 \%$.

Complications related to the laparoscopic access include retroperitoneal vascular damage, intestinal perforation, incisional hernia, wound infection, abdominal wall hemorrhage, and metastases of the trocar site. Although these complications are uncommon, they may lead to a significant increase in morbidity and mortality. ${ }^{8}$

In this regard, Veress needle insertion for the creation of pneumoperitoneum, a highly used technique, ${ }^{9}$ could lead to bowel damage or vascular lesions. According to Molloy et al, ${ }^{10}$ who evaluated 155987 gynecological procedures, Veress needle was used in $81 \%$ of cases. In addition, out of 17216 general surgery procedures, Veress needle was used in $48 \%$ of cases. ${ }^{10}$

\footnotetext{
I“A. Mirri” Sicily Zooprophilactic Institute, Palermo, Italy

${ }^{2}$ Department of Surgical, Oncological and Oral Sciences, University of Palermo, Palermo, Italy

${ }^{3}$ Euro-Mediterranean Institute of Science and Technology (IEMEST), Palermo, Italy

${ }^{4}$ C. Bua S.R.L., Bagheria, Italy

\section{Corresponding Author:}

Vincenzo Davide Palumbo, Department of Surgical, Oncological and Oral Sciences, University of Palermo, Via Del Vespro 129, 90I27 Palermo, Italy.

Email: vincenzodavide.palumbo@unipa.it
} 
In general, $30 \%$ to $50 \%$ of intestinal lesions and $13 \%$ to $50 \%$ of vascular lesions are diagnosed during intervention. ${ }^{10}$ Currently, bowel damage could be more likely linked to serious sequelae, due to their diagnostic delay; in this case, mortality rate can reach $2.5 \%$ to $5 \%{ }^{11}$

On the other hand, vascular damage is the much-feared complication in laparoscopic procedures, as it is considered one of the major causes of laparoscopic death, with a $15 \%$ mortality rate. ${ }^{12}$ Most of vascular lesions occur during the early stages of laparoscopy. As reported by several authors, $75 \%$ to $87.5 \%$ of the major vascular lesions occur during the insertion of Veress needle or the first trocar. ${ }^{13,14}$ The onset of these lesions is likely due to the proximity of the abdominal wall to the retroperitoneal vascular structures, and this is particularly true for those patients with scarce abdominal fat tissue, where this distance can be of only few centimeters. ${ }^{15}$

Colon lesions are the third cause of death due to laparoscopy, following important vascular damages and anesthesia complications, respectively. Unlike major vascular injuries, where the risk and the presentation of the damage are immediate, many intestinal injuries are usually not recognized at the time of the procedure. Consequently, patients often show symptoms of an acute perforative peritonitis, only during their postoperative period. This delay in the detection of intestinal injuries is an important cause of morbidity and mortality. ${ }^{15}$

A major survey of approximately 37000 gynecologic laparoscopies in the United States revealed an incidence of $0.16 \%$ of intestinal lesions. In general, according to Krishnakumar and Tambe, $39.8 \%$ of vascular and intestinal injuries are caused by the use of Veress needle, $37.9 \%$ of them are due to the insertion of the primary trocar, and $22 \%$ due to insertion of the secondary trocar. ${ }^{15}$

As mentioned above, Veress needle is blindly inserted into the abdomen, thus increasing the risk of iatrogenic lesions. Although relatively rare, even with increasing surgeon experience and the use of safety methods, these lesions still occur. Despite the prevalence reported being very low $(0.05 \%)$, the mortality rate resulting from these lesions ranges from $8 \%$ to $17 \% .{ }^{13}$ While hemorrhages can lead to death by hypovolemic shock, intestinal lesions can lead to peritonitis and death due to septicemia. ${ }^{13}$

An efficient and effective solution against the complications caused by Veress needle as well as a valid and safe alternative to further techniques for the creation of pneumoperitoneum is currently required. The need to refine Veress needle also derives from the small amount of improvements made to the device during the past decades.

The aim of this study is to overcome the complications associated with the insertion of Veress needle, hence improving its use and facilitating the rapid creation of pneumoperitoneum.

\section{Materials and Methods}

Thanks to the existing agreement between the University of Palermo and “A. Mirri" Sicily Experimental Zooprophylactic Institute, 30 large white female pigs, weighing 30 to $35 \mathrm{~kg}$, were enrolled from March 2013 to June 2016. All experiments were carried out in accordance with the provisions of the Legislative Decree No. 26 of March 4, 2014 about the protection of animals used for scientific purposes.

All surgical procedures were performed under general anesthesia, after premedication with zolazepam + tiletamine $(6.3 \mathrm{mg} / \mathrm{kg})+$ xylazine $(2.3 \mathrm{mg} / \mathrm{kg})$. Anesthesia was inducted with propofol $(0.5 \mathrm{mg} / \mathrm{kg})$; then, each animal was intubated. General anesthesia was maintained with $2 \%$ isofluorane. All pigs were submitted to a postoperative antibiotic treatment with oxytetracycline $(20 \mathrm{mg} / \mathrm{kg} / \mathrm{day}$, for 3 days). Twenty-four hours before surgery, all animals started fasting. On the day of the experiment, each animal was positioned in supine position, with the 4 limbs fixed to the operating table; trichotomy of the abdomen and disinfection of the operating field with $10 \%$ iodine povidone were performed. During surgery, heart rate, blood pressure, blood oxygen saturation, and central venous pressure were monitored. Infusion of liquids and drugs was performed through a central venous catheter positioned into the jugular vein and appropriately tunneled into the subcutaneous tissue of the neck. ${ }^{16}$

The study consisted of 2 phases. In phase 1, the feasibility study ( 2 experiments on $1 \mathrm{pig}$ ), a common plunger was modified in order to allow the passage of a $15-\mathrm{cm}$ Veress needle. In this case, the wooden handle was cut at $10 \mathrm{~cm}$ from the rubber cuff and a hole of about $1 \mathrm{~mm}$ in diameter, along the longitudinal axis, was drilled (Figure 1).

After careful shaving, cleansing, and disinfection of the skin, the sucker was applied to the pig's umbilical region. The subsequent negative pressure allowed the abdominal wall to be lifted in a simple and effective way, moving it away from the underlying viscera. The Veress needle was then inserted into the umbilical scar through the perforated handle, and pneumoperitoneum was created. In this first phase, failures were likely due to craftsmanship of the prototype: the handle was not ergonomic, and the needle slider system did not adhere perfectly to the needle, provoking air leaks.

Phase 2 provided the creation of a new plastic sucker. The rubber cuff of the previous model was substituted with a transparent plastic suction cup, whereas the wooden handle was removed and substituted with a rigid plastic handle surmounted by 2 paired rings, in order to ameliorate grip during abdomen lifting (Figure 2).

Prototype 2 was created by making the suction cup softer (with a particular plastic compound) and sharper 


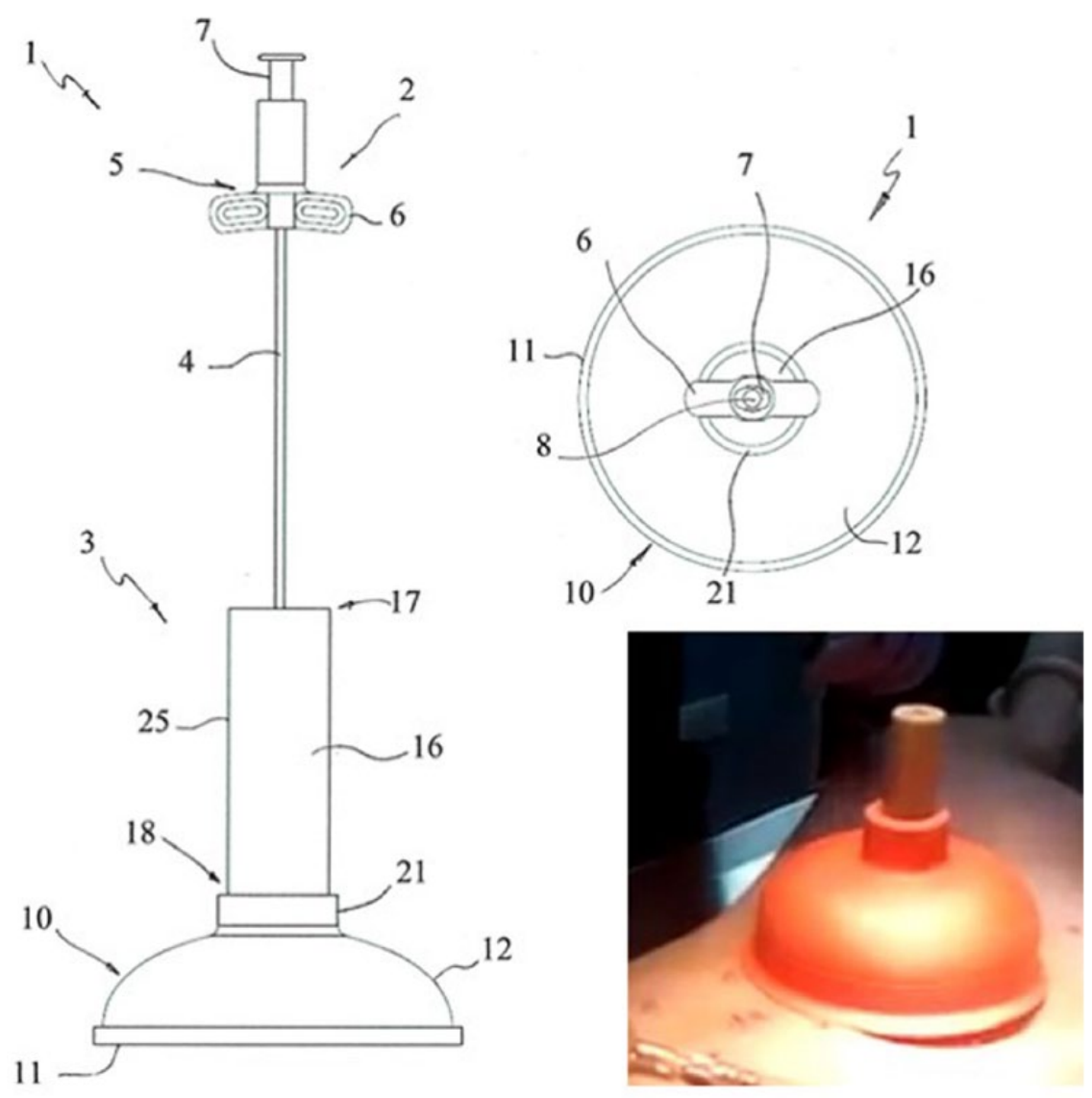

Figure I. Prototype 0: Veress needle on a modified plunger. The wooden handle was cut at $10 \mathrm{~cm}$ from the rubber cuff and a hole of about $1 \mathrm{~mm}$ in diameter, along the longitudinal axis, was drilled, in order to allow the passage of a $15-\mathrm{cm}$ Veress needle.

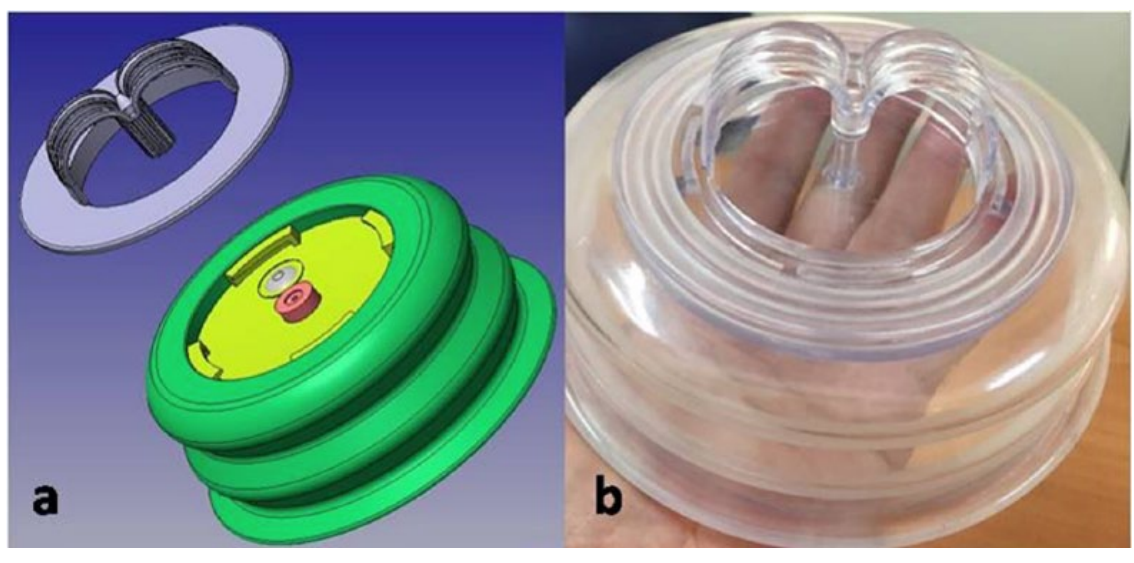

Figure 2. Prototype I: (a) 3D virtual model, (b) plastic model.

(its margins were sharpened to better adhere to the skin). Finally, a drain valve was inserted into the rigid part of the suction cup, making the compression phase easier and more rapid (Figure 3). Before each experiment, a 5-mm trocar was inserted at the intersection of the anterior axillary line and the transverse umbilical one, with classic closed technique, to allow visualization of the safety room created by the device. 


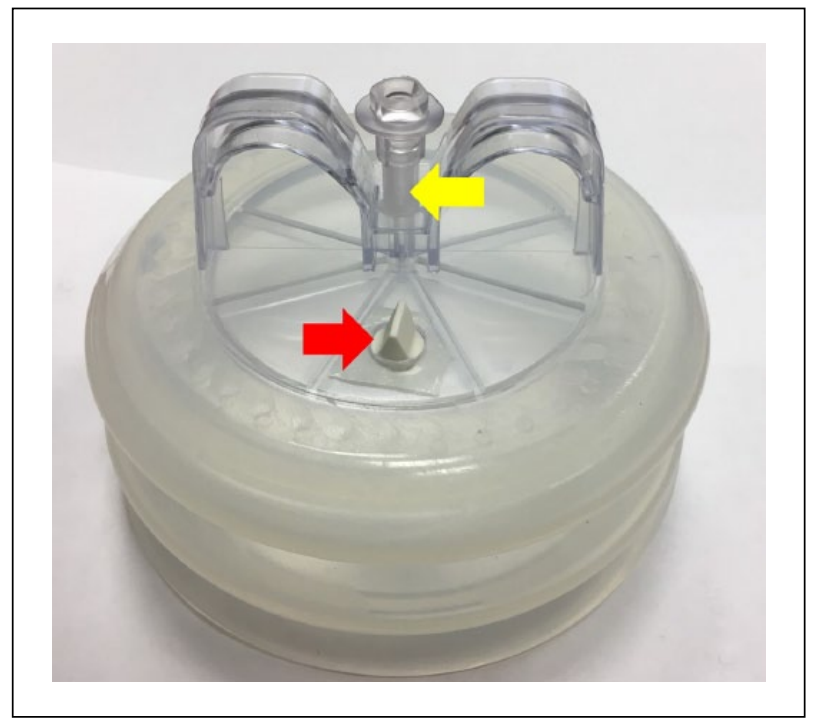

Figure 3. OneShot-M ultimate prototype: noteworthy is the unidirectional vent valve (red arrow) and the needle slider system (yellow arrow) with the double rubber gasket at the external end of the introduction channel.

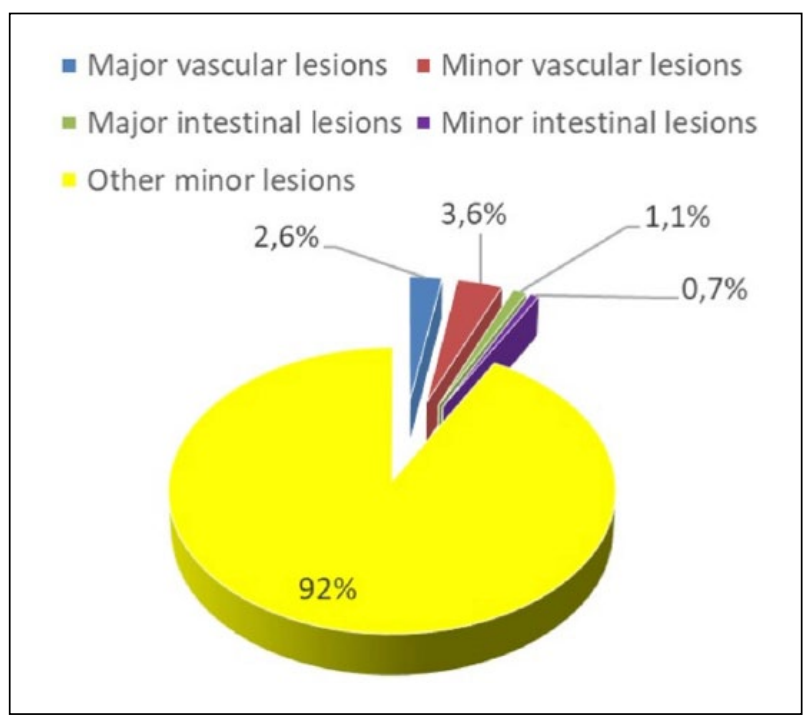

Figure 4. Veress needle lesion rates. ${ }^{10}$

\section{Results}

In phase 1, 3 attempts out of 10 with prototype 0 (in 1 pig) resulted positive. In phase 2, 2 attempts out of 10 with prototype 1 resulted positive (1 pig). This prototype proved ineffective due to the suction cuff stiffness and the convexity of the contact edge, which did not adhere to the skin. This made it difficult to get the vacuum and the following lifting grip. Prototype 2, manufactured using a less rigid plastic material, was provided by a nonconvex margin in order to achieve better results (Figure 2). A quicker and safer pneumoperitoneum was obtained in 7 out of 10 attempts ( 1 pig). Prototype 3 (Figure 3 ) was provided with a vent valve on the flange, ensuring a quicker and more homogeneous emptying of the suction cuff. Adhesion of the bell to the skin improved, and the pneumoperitoneum was quickly obtained in all 10 attempts (1 pig). Subsequently, this method was applied to 26 laparoscopic procedures (26 pigs) of several specialist branches (general surgery, gynecology, pediatrics, urology) without any intraoperative and postoperative complications linked to Veress needle (see supplemental material).

\section{Discussion}

Over the past few years, a safer and easier method to insert trocars during the early stages of laparoscopic procedures has been investigated. Currently, there are 4 basic techniques used to create the pneumoperitoneum: the closed technique with "blind" insertion of a Veress needle, direct trocar insertion (DTI), optic trocar insertion, and laparoscopy with open (Hasson) technique. ${ }^{17}$

Although many strategies have been adopted in order to reduce the related complications, poor results have been achieved by the Veress needle insertion technique. The navel usually coincides with the sacral promontory, which in turn coincides with the bifurcation of large vessels; it thus is crucial to be very careful in avoiding injuries of these vessels. Most important, in obese patients, the navel will be located down anatomically; this should be kept in mind when accessing the abdomen. ${ }^{18}$

Therefore, the creation of pneumoperitoneum currently represents the most crucial phase of the laparoscopic procedures, being burdened by several, even life-threatening, complications. ${ }^{10,19}$ Azevedo et $\mathrm{al}^{4}$ carried out a systematic review of Veress needle vascular injury cases that occurred during the creation of pneumoperitoneum. The collected data provided information on 696 502 cases of abdominal laparoscopic procedures, published between 1966 and 2007 . $^{4}$

Revision of these articles led to the detection of 1575 injuries caused by Veress needle, about $0.23 \%$ of the total procedures. All bowel injuries are listed in Table 1 and represented in Figure 4.

Further data obtained from the literature showed that 10 of the $13(76.9 \%)$ major vascular lesions were derived from open surgical techniques. Only hemodynamically stable patients, with nondiffuse retroperitoneal hematomas, were monitored over time. With regard to minor vascular lesions, only 2 cases were reported: in the first case, a damage of a greater omentum vein was repaired laparoscopically ${ }^{20}$; in the second case, a lesion of the upper mesenteric artery was instead fixed in laparotomy. ${ }^{21}$ According to some data, the average incidence of major vascular injuries due to Veress needle is about $0.1 \%$. 
Table I. Lesions Caused by Veress Needle. ${ }^{4}$

\begin{tabular}{lcc}
\hline Type of Lesion & $\begin{array}{c}\text { No. of } \\
\text { Injuries }\end{array}$ & $\begin{array}{c}\text { \% of Cases } \\
\text { Studied }\end{array}$ \\
\hline Major injury to hollow viscera & 17 & 0.0025 \\
Colon & 8 & \\
Cecum & 1 & \\
Transverse & 2 & \\
Sigmoid & 2 & \\
Not specified & 3 & \\
Not specified & 9 & \\
Minor injuries to hollow viscera & $1 \mathrm{I}$ & 0.0016 \\
Stomach & 9 & \\
Bladder & 2 & \\
Total & 28 & 0.004 \\
\hline
\end{tabular}

A study conducted by the US Food and Drug Administration between 1993 and 1996 showed a total of 32 deaths out of 629 trocars injuries, with $81 \%$ of deaths due to severe vascular injuries and 19 from intestinal lesions. ${ }^{14}$ Most cases of trocar injuries were nonfatal vascular lesions, followed by nonfatal visceral lesions, such as intestinal and abdominal hematomas. ${ }^{22}$ Among vascular injuries, the most commonly injured vessels were the aorta, the inferior vena cava, iliac, ${ }^{23}$ and epigastric vessels ${ }^{24}$ (lateral trocars). Bowel lesions were mostly repaired by laparotomy $(58.3 \%)$. Literature describes only 484 cases of minor lesions (33.8\%). A summary of all reported cases of injury caused by Veress needle is shown in Table 2 .

According to aforementioned data, the insertion of Veress needle for the creation of pneumoperitoneum is obviously not exempt from risks. Unfortunately, these evidences do not confer great security to the other abdomen entry techniques. The use of open technique for the creation of pneumoperitoneum involves also a certain level of complications.

In this regard, our device proved to be a valid and safe method for the creation of pneumoperitoneum, by reducing complications due to the introduction of the Veress needle into the abdominal cavity. Its viability can be compared with other alternatives built for the same purpose. In recent decades, many techniques and guidelines have in fact been introduced to eliminate the complications arising from the creation of pneumoperitoneum. ${ }^{25}$

The insertion of Veress needle and the first trocar could be considered the most dangerous phase of laparoscopy: both procedures account for $40 \%$ of laparoscopic complications and most of the deaths. ${ }^{2}$ Therefore, the optimization of abdominal cavity entry technique is essential to ameliorate the course of laparoscopic procedures. ${ }^{26}$ Currently, there is no agreement about abdomen entry techniques to be chosen in order to avoid unpleasant or even life-threatening complications.
Although several studies have reported a connection between major vascular damages and closed abdominal laparoscopic entry, there is no agreement about the superiority of one method over the others. ${ }^{27}$ In May 2007, Aragon Surgical (Palo Alto, CA) introduced LapCap, a bell-shaped polycarbonate dome containing a passthrough port for introduction of a standard Veress needle and a vacuum port for attachment to a standard hospital vacuum line. The LapCap is a clever and well-designed device, based on excellent anatomic and surgical principles, very similar to OneShoot-M. The first method uses a bell-shaped vacuum to elevate the abdomen over the umbilicus and favor Veress insertion safely, whereas the latter uses manual force to obtain the same result. OneShot-M was patented in 2017 and will be marketed by 2018 .

The insertion of Veress needle is, however, the method most used by gynecologists; open technique is more commonly used by young generations of general surgeons. ${ }^{28}$ One of the widely used techniques and an alternative to closed technique is the so-called Hasson technique. Hasson first described such an entry technique in $1971 .{ }^{29}$ The open-entry technique is preferred by general surgeons, although its advantages over other entry techniques cannot be proven clearly.

The open technique probably leads to less severe vascular damage, and if any injury occurs, its detection and reparation could be performed in an easier way. However, the cross-sectional process of the different layers of the abdominal wall may take a long time. In addition, open access leads to irritating air leakage due to large incision, especially in obese patients, and is associated with a higher rate of wound infection. ${ }^{30}$ Several randomized studies and a Cochrane analysis did not report significant evidence of safety for both techniques. ${ }^{31-33}$

The Swiss Association for Laparoscopy and Toracoscopic Surgery (SALTS) collected prospective data on $90.3 \%$ of low-risk patients submitted to various laparoscopic procedures between 1995 and 1997 (14 243 patients, male/female ratio 0.7$).{ }^{20}$ The insertion of the umbilical trocar caused 8 visceral damages: 6 lesions followed blind insertion and 2 occurred after Hasson entry technique. In contrast to the results published by Sigman et al, ${ }^{34}$ Bonjer et al, ${ }^{35}$ and Zaraca et $a 1,{ }^{36}$ the authors argued that the open-access method could not be superior to closed technique, for the creation of pneumoperitoneum. ${ }^{20}$

In 2016, a prospective study was performed on a total of 2579 laparoscopic surgeries conducted between January 2005 and December 2015, concerning another openaccess method used in laparoscopic practice since 1998, which has advantages in comparison to traditional closed techniques, but that does not solve all accidents related to 
Table 2. Lesions Caused by Veress Needle During Laparoscopy and Treatment.

\begin{tabular}{|c|c|c|}
\hline Reference & Type of Lesion & Treatment \\
\hline Dunne et $\mathrm{al}^{28}$ & Two unspecified vascular lesions & Laparotomy, without further complications \\
\hline Pasic $^{29}$ & Inferior cava vein & Laparotomy and venography \\
\hline \multirow[t]{2}{*}{ Alkatout et $\mathrm{al}^{30}$} & Gaseous embolism & Cardiopulmonary resuscitation with clinical sequelae \\
\hline & & Prolonged hospital stay \\
\hline $\begin{array}{l}\text { Royal College of Obstetricians } \\
\text { and Gynaecologists }{ }^{31}\end{array}$ & Pneumoamnion & Fetal death \\
\hline Bemelman et $\mathrm{al}^{32}$ & Bladder & Antibiotics and catheterization \\
\hline Garry $^{33}$ & Iliac vessels & Suture of the lesion without complications \\
\hline \multirow[t]{2}{*}{ Sigman et $\mathrm{al}^{34}$} & Common iliac artery & Death \\
\hline & Aorta & Suture of the lesion \\
\hline Bonjer et $\mathrm{al}^{35}$ & Internal iliac artery & Laparotomy and suture of the lesion \\
\hline Zaraca et $\mathrm{al}^{36}$ & Left common iliac artery and vein & Embolization-death \\
\hline Uranues et $\mathrm{al}^{37}$ & Left common iliac artery and vein & $\begin{array}{l}\text { Laparotomy, grafting for the arterial lesion and } \\
\text { venography, without complications }\end{array}$ \\
\hline Nevler et $\mathrm{al}^{38}$ & Aorta & Death \\
\hline
\end{tabular}

access. With this technique, detection of subperitoneal structures is simplified, allowing a timely treatment of eventual small injuries. Furthermore, the fascial suture, once closed tightly, prevents gas leakage. ${ }^{37}$ In this study conducted by Uranues et al, ${ }^{37} 2$ patients of the open-entry group reported accidental injuries. One of them, a 69-yearold woman who underwent surgery for a large incisional hernia, suffered a serious lesion of the descending colon after entering the trocar through her left flank. The lesion was immediately detected and repaired without laparotomy. ${ }^{37}$ The second patient was a 74-year-old man who suffered from a massive hiatal hernia; in this case, a lesion in the small intestine was fixed through a slightly enlarged fascial incision. Anti-reflux plastic surgery was then completed laparoscopically. ${ }^{37}$ The described technique demonstrated that better visualization of abdominal cavity elements given by open technique does not correspond to a decrease in visceral lesion risk.

Other methods of Veress needle entry have been introduced, including a study carried out by Nevler et al. ${ }^{38}$ This innovative approach should reduce the complications associated with the "blind" entrance of Veress needle. ${ }^{38}$ What differs, in terms of practical maneuvers, is the presence of an expandable element located in the tip of Veress needle that allows it to adhere to the abdominal wall, once it is inflated. This technique also allows insertion of the first trocar using Veress needle as a guide and thus eliminates the need for a second "blind" hole. Unfortunately, the technique described above, although it could reduce the incidence of injuries due to first trocar insertion, does not erase completely the risks connected to Veress needle. In addition, a supplementary strength should be applied for abdominal wall lifting, compared with the soft maneuvers required by our suction cup.
There are other alternatives to Veress needle. Optical trocar insertion has been demonstrated to allow safe access for obese patients; unfortunately, it still maintains the risk of injuries during trocar insertion. ${ }^{39} \mathrm{DTI}^{26}$ has been welcomed with some degree of popularity. However, a meta-analysis on the efficacy of DTI, ${ }^{26}$ while detecting a lower rate of incorrect entry, extraperitoneal insufflation, and omental lesions, did not demonstrate a significant reduction of complications.

The main difficulty for an objective evaluation of the results of new access techniques and new access devices is the low incidence of major complications. The creation of a large-scale controlled clinical study would require a great amount of patients for each study arm. Unfortunately, due to the costs of such a study, current data are mainly based on physical and physiological laboratory tests, controlled randomized clinical trials, and small-scale meta-analyses. $^{37}$

\section{Conclusions}

The use of the proposed device showed an induction time as quick as the standard laparoscopic closed abdominal entry. The patented device is cheap and allows safe abdominal access. In addition, abdominal entry is much faster than classic open techniques.

Intraabdominal observations demonstrated not only a significant displacement of the abdominal wall but also, and above all, the presence of a periumbilical dome, adherent to the suction cup, which creates a "safety room" where the needle can be inserted, preventing damages to the anatomical structures. The space obtained with the initial suction dome allowed the operator to slightly lift the abdomen without strong traction. The positioning of a 
vent valve on the flange and of a double rubber gasket at the external end of the Veress needle introduction channel (Figure 2a) guaranteed the durable vacuum in prototype 3 and the "dome effect" on the abdominal wall.

In the near future, the use of the proposed device could be implemented, allowing the creation of a low $\mathrm{CO}_{2}$ pressure on even gasless laparoscopic operative field. We are also considering completing the system by adding an automatic snap needle with a controlled penetration, based on the thickness of the abdominal wall. It has been demonstrated, in fact, that a needle penetration of only 1 $\mathrm{cm}$ into the peritoneal cavity could guarantee the perfect creation of pneumoperitoneum. The good results obtained on animal model will necessarily have to be confirmed by a clinical trial on humans.

\section{Authors' Note}

The article was presented orally at the 29th Conference of the International Society for Medical Innovation and Technology (SMIT) held in Turin, Italy, November 9 and 10, 2017.

\section{Author Contributions}

Study concept and design: Giovanni Cassata, Antonino De Luca, Attilio Ignazio Lo Monte

Acquisition of data: Vincenzo Davide Palumbo, Salvatore Fazzotta, Luca Cicero

Analysis and interpretation: Vincenzo Davide Palumbo, Giuseppe Damiano, Salvatore

Study supervision: Attilio Ignazio Lo Monte

\section{Declaration of Conflicting Interests}

The author(s) declared no potential conflicts of interest with respect to the research, authorship, and/or publication of this article.

\section{Funding}

The author(s) received no financial support for the research, authorship, and/or publication of this article.

\section{Supplemental Material}

Supplemental material for this article is available online.

\section{ORCID iD}

Vincenzo Davide Palumbo (iD) http://orcid.org/0000-00024603-2011

\section{References}

1. Simforoosh N, Basiri A, Ziaee SA, et al. Major vascular injury in laparoscopic urology. JSLS. 2014;18:e2014.00283.

2. Pickett SD, Rodewald KJ, Billow MR, Giannios NM, Hurd WW. Avoiding major vessel injury during laparoscopic instrumentinsertion.Obstet GynecolClinNorthAm.2010;37: 387-397.
3. Vilos GA, Ternamian A, Dempster J, Laberge PY; Clinical Practice Gynaecology Committee. Laparoscopic entry: a review of techniques, technologies, and complications. $J$ Obstet Gynaecol Can. 2007;29:433-447.

4. Azevedo JL, Azevedo OC, Miyahira SA, et al. Injuries caused by Veress needle insertion for creation of pneumoperitoneum: a systematic literature review. Surg Endosc. 2009;23:1428-1432.

5. Jansen FW, Kapiteyn K, Trimbos-Kemper T, Herman SJ, Trimbos JB. Complications of laparoscopy: a prospective multicentre and observational study. Br J Obstet Gynaecol. 1997;104:595-600.

6. Jansen FW, Kolkman W, Bakkum EA, et al. Complications of laparoscopy: an inquiry about closed- versus open-entry technique. Am J Obstet Gynecol. 2004;190:634-638.

7. Magrina JF. Complications of laparoscopic surgery. Clin Obstet Gynecol. 2002;45:469-480.

8. Munro MG. Laparoscopic access: complications, technologies, and techniques. Curr Opin Obstet Gynecol. 2002; 14:365-374.

9. Périssat J, Vitale GC. Laparoscopic cholecystectomy: gateway to the future. Am J Surg. 1991;161:408.

10. Molloy D, Kaloo PD, Cooper M, Nguyen TV. Laparoscopic entry: a literature review and analysis of techniques and complications of primary port entry. Aust $N Z J$ Obstet Gynaecol. 2002;42:246-254.

11. Olsen DO. Laparoscopic cholecystectomy. Am J Surg. 1991;161:339-344.

12. Chandler JG, Corson SL, Way LW. Three spectra of laparoscopic entry access injuries. J Am Coll Surg. 2001;192: 478-491.

13. Chapron CM, Pierre F, Lacroix S, Querleu D, Lansac J, Dubuisson JB. Major vascular injuries during gynecologic laparoscopy. J Am Coll Surg. 1997;185:461-465.

14. Opitz I, Gantert W, Giger U, Kocher T, Krähenbühl L. Bleeding remains a major complication during laparoscopic surgery: analysis of the SALTS database. Langenbecks Arch Surg. 2005;390:128-133.

15. Krishnakumar S, Tambe P. Entry complications in laparoscopic surgery. J Gynecol Endosc Surg. 2009;1:4-11.

16. Lombardo C, Damiano G, Cassata G, et al. Surgical vascular access in the porcine model for long-term repeated blood sampling. Acta Biomed. 2010;81:101-103.

17. Neudecker J, Sauerland S, Neugebauer E, et al. The European Association for Endoscopic Surgery Clinical practice guideline on the pneumoperitoneum for laparoscopic surgery. Surg Endosc. 2002;16:1121-1143.

18. Sotelo R, Bragayrac LAN, Machuca V, Cortes RG, Azhar RA. Avoiding and managing vascular injury during roboticassisted radical prostatectomy. Ther Adv Urol. 2015;7:41-48.

19. Ahmad G, Duffy JM, Philips K, Watson A. Laparoscopic entry techniques. Cochrane Database Syst Rev. 2008;(2): CD006583.

20. Schäfer M, Lauper M, Krähenbühl L. Trocar and Veress needle injuries during laparoscopy. Surg Endosc. 2001;15: 275-280.

21. Harkki-Siren P. The incidence of entry-related laparoscopic injuries in Finland. Gynaecol Endosc. 1999;8:335-338. 
22. Bhoyrul S, Vierra MA, Nezhat CR, Krummel TM, Way LW. Trocar injuries in laparoscopic surgery. $\mathrm{J} \mathrm{Am}$ Coll Surg. 2001;192:677-683.

23. Castillo O, Peacock L, Vitagliano G, Pinto I, Portalier P. Laparoscopic repair of an iliac artery injury during radical cystoprostatectomy. Surg Laparosc Endosc Percutan Tech. 2008;18:315-318.

24. Arias JGP, Quintanilla MG, Tamayo AL, Odriozola AA, González GI. Complications and incidences in our first 250 robotic radical prostatectomies [in Spanish]. Acta Urol Esp. 2010;34:428-439.

25. Taye MK, Fazal SA, Pegu D, Saikia D. Open versus closed laparoscopy: yet an unresolved controversy. J Clin Diagn Res. 2016;10:QC04-QC07.

26. Agresta F, Mazzarolo G, Bedin N. Direct trocar insertion for laparoscopy. JSLS. 2012;16:255-259.

27. Tinelli A, Malvasi A, Istre O, Keckstein J, Stark M, Mettler L. Abdominal access in gynaecological laparoscopy: a comparison between direct optical and blind closed access by Veress needle. Eur J Obstet Gynecol Reprod Biol. 2010;148:191-194.

28. Dunne N, Booth MI, Dehn TC. Establishing pneumoperitoneum: Veress or Hasson? The debate continues. Ann R Coll Surg Engl. 2011;93:22-24.

29. Pasic R. Creation of pneumoperitoneum and trocar insertion techniques. In: Pasic R, Levine R eds. A Practical Manual of Laparoscopy: A Clinical Cookbook. Abingdon, England: Informa Healthcare; 2007:57-74.

30. Alkatout I, Mettler L, Maass N, Noé GK, Elessawy M. Abdominal anatomy in the context of port placement and trocars. J Turk Ger Gynecol Assoc. 2015;16:241-251.
31. Royal College of Obstetricians and Gynaecologists. Laparoscopic injuries (Green-top Guideline No. 49). https://www. rcog.org.uk/en/guidelines-research-services/guidelines/ gtg49/. Published January 5, 2008. Accessed August 23, 2018.

32. Bemelman WA, Dunker MS, Busch OR, Den Boer KT, de Wit LT, Gouma DJ. Efficacy of establishment of pneumoperitoneum with the Veress needle, Hasson trocar, and modified blunt trocar (TrocDoc): a randomized study. $J$ Laparoendosc Adv Surg Tech A. 2000;10:325-330.

33. Garry R. Laparoscopic surgery. Best Pract Res Clin Obstet Gynaecol. 2006;20:89-104.

34. Sigman HH, Fried GM, Garzon J, et al. Risks of blind versus open approach to celiotomy for laparoscopic surgery. Surg Laparosc Endosc. 1993;3:296-299.

35. Bonjer HJ, Hazebroek EJ, Kazemier G, Giuffrida MC, Meijer WS, Lange JF. Open versus closed establishment of pneumoperitoneum in laparoscopic surgery. Br J Surg. 1997;84;599-602.

36. Zaraca F, Catarci M, Gosselti F, Mulieri G, Carboni M. Routine use of open laparoscopy: 1,006 consecutive cases. J Laparoendosc Adv Surg Tech A. 1999;9:75-80.

37. Uranues S, Ozkan OV, Tomasch G. Safe and easy access technique for the first trocar in laparoscopic surgery. Langenbecks Arch Surg. 2016;401:909-912.

38. Nevler A, Har-Zahav G, Rosin D, Gutman M. Safer trocar insertion for closed laparoscopic access: ex vivo assessment of an improved Veress needle. Surg Endosc. 2016;30: 779-782.

39. McKernan JB, Finley CR Experience with optical trocar in performing laparoscopic procedures. Surg Laparosc Endosc Percutan Tech. 2002;12:96-99. 